\title{
Educação Ambiental: atuação do gestor escolar e uso das tecnologias da alfabetização ao ensino médio
}

\author{
Environmental education: performance of the school manager and use \\ of literacy technologies to High School
}

\section{Maria Valdete da Silva Bolsoni ${ }^{1}$ Valdecira Aparecida da Silva Moreira ${ }^{2}$ Valdicéia de Cássia da Silva Balbinot ${ }^{3}$}

\author{
1 Mestre em Ciencias da Educação.UDS. E-mail: valdetebolsoni@hotmail.com \\ 2 Mestre em Ciencias da Educação. em 16 de janeiro de 2018 pela UDS, Pedagoga. Professora da rede estadual de Ensino de Rondônia. Especialista \\ em Metodos e Técnicas de Ensino; Gestão Escolar; Mídias na Educação. E-mail: valdeciracolorado@hotmail.com \\ 3 Mestra em Ciencias da Educação. Universidad de Desarrollo Sustentable. E-mail: valdiceia_balbinot@hotmail.com
}

RESUMO: O artigo objetiva socializar resultado de pesquisa sobre implicações da atuação do gestor escolar e uso de tecnologias digitais na Educação Ambiental. Metodologicamente utilizou-se a pesquisa bibliográfica, a partir da análise da Educação Ambiental, relacionando políticas públicas e legislações às questões pedagógicas. Constatou-se que a temática é abordada nas escolas e promove incentivo aos estudantes em relação aos cuidados com o ambiente. Entretanto, há necessidade de investimentos na formação dos gestores, sendo necessário prover meios para aquisição, reparos e manutenção de equipamentos tecnológicos, possibilitando às escolas mapear as perspectivas inovadoras e corretivas a serem colocadas em prática na educação ambiental.

Palavras chave: Educação Ambiental. Alfabetização. Gestão Escolar. Tecnologia. Ensino Médio.

ABSTRACT: This article aims to socialize research results on the implications of school manager performance and the use of digital technologies in Environmental Education. Methodologically we used the bibliographic research, from the analysis of Environmental Education, relating public policies and legislations to pedagogical issues. It was found that the theme is addressed in schools and promotes encouragement to students in relation to environmental care. However, there is a need for investments in the training of managers, being necessary to provide means for the acquisition, repair and maintenance of technological equipment, enabling schools to map the innovative and corrective perspectives to be put into practice in environmental education.

Keywords: Environmental Education. Literacy. School management. Technology. High school.

SUMÁRIO: Introdução - 1 Retrospectiva histórica: Educação Ambiental no Brasil - 2 Educação Ambiental e as ações pedagógicas - Considerações Finais - Referenciais.

\section{INTRODUÇÃO}

O ritmo acelerado do desenvolvimento tecnológico e científico proporcionam modificações constantes na sociedade promovendo demandas tecnológicas em todas às áreas. Nas escolas, cabe ao gestor permanecer atualizado, liderando a inserção de inovações tecnológicas no contexto escolar, no intuito de auxiliar o fazer pedagógico inovador e eficiente, pois quando se trata de Educação Ambiental o assunto é sério. Nesse interim, observe Moran. 
As tecnologias digitais facilitam a pesquisa, a comunicação e a divulgação em rede. A gestão das tecnologias pelas escolas passa por três etapas, até o momento. Na primeira, as tecnologias são utilizadas para melhorar o que já se vinha fazendo, como o desempenho, a gestão, para automatizar processos e diminuir custos. Na segunda etapa, a escola insere parcialmente as tecnologias no projeto educacional. Cria uma página na Internet ou Portal com algumas ferramentas de pesquisa e comunicação, divulga textos e endereços interessantes, desenvolve alguns projetos, há atividades no laboratório de informática, introduz aos poucos as tecnologias móveis, mas mantém intocados estrutura de aulas, disciplinas e horários. Na terceira, com o amadurecimento da sua implantação e o avanço da integração das tecnologias móveis, as escolas e as universidades repensam o seu projeto pedagógico, o seu plano estratégico e introduzem mudanças metodológicas e curriculares significativas como a flexibilização parcial do currículo, com atividades a distância combinadas as presenciais (MORAN, 2013, p. 36).

O uso dos recursos digitais tem uso garantido na educação ambiental, principalmente a Internet, como apoio para a pesquisa, para a realização de atividades discentes, para a comunicação com os alunos e dos alunos entre si, para a integração entre grupos dentro e fora da turma, para publicação de páginas web, blogs e vídeos, para a participação em redes sociais, entre muitas outras possibilidades.

Em retomada histórica sobre a educação ambiental, verifica-se que atitudes indevidas resultam em graves consequências a saúde do planeta demandando milhares de ano para se reconstituir. No início da civilização o meio ambiente e o homem viviam de forma equilibrada, ou seja, a natureza, o planeta era autossustentável. No entanto, o aumento da população e a expansão urbana geraram o desequilíbrio ambiental agravado pelo desmatamento sem planejamento e altos níveis de consumo e descarte de lixo.

Considerando que o processo histórico é construído pela educação a qual exerce função ímpar, capaz de transformar a história cultural de um povo, se propõe a pesquisa sobre fatores históricos, legais e pedagógicos pertinentes a Educação Ambiental no Brasil. Sobre a necessidade de se investigar essa área sob a perspectiva histórica, Saviani afirma que

[...] tem profundas implicações para a pesquisa educacional, vez que o significado da educação está intimamente entrelaçado ao significado de História. E no âmbito da investigação histórico-educativa essa implicação é duplamente reforçada do ponto de vista do objeto, em razão da determinação histórica que exerce sobre o fenômeno educativo, e do ponto de vista do enfoque, dado que pesquisar em história da educação é investigar o objeto educação sob a perspectiva histórica (SAVIANI, 1998 p,11-12).

O autor defende que para compreender o processo histórico de pesquisa nas ciências humanas é necessário fazer uso de diferentes fontes que possam contribuir para reconstrução da pesquisa. Embasado neste pressuposto, a presente pesquisa parte da catalogação de fontes primárias e secundárias que possibilitem a reconstrução da história da educação ambiental no Brasil, refletindo sobre principais resultados publicados.

Ressalta-se que o papel da equipe gestora da escola é estimular e garantir ações, procedimentos didáticos e pedagógicos que despertem habilidades em cuidar do ambiente em que se vive. A tecnologia pode e deve ser utilizada para evidenciar em tempo real o desiquilíbrio ambiental e promover pesquisas pertinentes a ações simples e passiveis de práticas sociais e protagonismo infantil e juvenil nas turmas de alfabetização ao ensino médio.

\section{RETROSPECTIVA HISTÓRICA: EDUCAÇÃO AMBIENTAL NO BRASIL}

Leite (2015), evidenciou que no Brasil, a discussão sobre educação ambiental precedeu à sua 
institucionalização, ou seja, na década de 1970, período em que segundo o autor verificava-se a existência de um movimento ambientalista, buscava-se articular ações com as manifestações em defesa da liberdade democrática, chamando a atenção para o imperativo da preservação ambiental. Segundo este autor

A institucionalização de iniciativas contemplando a educação ambiental emerge em 1973, com a criação da Secretaria Especial do Meio Ambiente - SEMA, vinculada ao então Ministério do Interior. Na década seguinte, em 1981, mediante a Lei 9.398/813, instituiu-se a Política Nacional de Meio Ambiente - PNMA (LEITE, 2015, p.2).

Em 1973 com a criação da Secretaria Especial do Meio Ambiente (SEMA) outras iniciativas foram criadas em defesa das questões ambientais, no entanto este ano representou marco importante para a educação ambiental. A história da Educação Ambiental registra que no ano de 1989, outro passo importante foi conquistado com a criação do Instituto Brasileiro do Meio Ambiente (IBAMA) e mobilização social, como a exemplo, a Conferência Rio ECO 92. A este respeito Leite (2015) aborda

Em 1989, foi criado o Instituto Brasileiro do Meio Ambiente (IBAMA), e em 1991, por ocasião da Conferência Rio ECO 92, a Comissão Interministerial que tratava da sua preparação considerou a EA como um dos principais instrumentos da política ambiental brasileira. Dessa maneira, foram instituídas duas instâncias no âmbito do Poder Executivo com o propósito de tratar especificamente da mesma, quais sejam: o Grupo de Trabalho de Educação Ambiental do MEC, que em 1993 se transformou na Coordenação Geral de Educação Ambiental (COEA/MEC), e a Divisão de Educação Ambiental do IBAMA, cujas competências institucionais foram definidas no sentido de representar um marco para a institucionalização da política de Educação Ambiental na esfera do Sistema Nacional de Meio Ambiente (SISNAMA). Em 1994, foi criado o Ministério do Meio Ambiente (MMA) (LEITE, 2015, p. 3).

Em decorrência das ações ambientais, torna-se notório novo patamar da natureza e da sociedade que se formam em contexto histórico, a cada dia consta-se adesão de entidades governamentais e não governamentais que se unem em defesa do meio ambiente. Em relação à educação ambiental, Pádua (2010) enfatiza que

O importante é permanecer atento e aberto em cada situação de pesquisa. Em certas situações os fatores biofísicos são decisivos. Em outras a tecnologia ou as visões de mundo podem ser decisivas. Em todas as situações, no entanto, o biofísico, o social e o cultural estão presentes. Nos diferentes casos, o que se percebe são sistemas abertos e que se modificam no andamento da história. Os próprios relacionamentos entre todos os componentes da interação - onde todos são relevantes, mesmo que em diferentes níveis - constroem, destroem e reconstroem inúmeras formas materiais e culturais. No sentido mais profundo, o desafio analítico é o de superar as divisões rígidas e dualistas entre natureza e sociedade, em favor de uma leitura dinâmica e integrativa, fundada na observação do mundo que se constrói no rio do tempo (PÁDUA, 2010, p. 10).

No século XXI, na era da globalização a tecnologia se configura como parceira aliada ao progresso e desenvolvimento do país, neste sentido Pádua (2010), defende que em algumas situações a tecnologia ou as visões de mundo podem ser decisivas, ou seja, em tempos da interdisciplinaridade, se reconhece que a criação de políticas públicas e legislação por si só não resolvem os problemas ambientais globais, neste interim a ajuda da ciência e da tecnologia, contribuem favoravelmente para a construção do planeta auto sustentável, garantindo melhorias na qualidade de vida para todos.

Para Barbosa (2008, p. 3), "temas ambientais e outros, como gênero e etnicidade, ocupam cada vez 
mais espaços no debate científico e produção teórica, como também nas políticas públicas”. Em diferentes momentos da história, temas em evidência em cada época, apresentam-se associados a história e as produções dos seres humanos. A Constituição da República Federativa do Brasil (CRFB), de 1988 evidencia preocupação em relação ao meio ambiente ao garantir por força da legislação a necessidade de meio ambiente ecologicamente equilibrado, determinando que

Todos têm direito ao meio ambiente ecologicamente equilibrado, bem de uso comum do povo e essencial à sadia qualidade de vida, impondo-se ao poder público e à coletividade o dever de defendê-lo e preservá-lo para as presentes e futuras gerações (BRASIL, CRFB, 1988).

A exemplo da CRFB de 1988, diversas leis e normativas foram criadas para garantir a sustentabilidade do planeta, com foco na busca pela a responsabilidade coletiva da população. Rodrigues e Colesant (2008) apresenta quadro síntese contendo principais documentos legais pertinentes a educação ambiental no Brasil.

Figura 1 - Documentos nacionais direcionados à EA

\begin{tabular}{|l|l|}
\hline Documento & Pontos Principais \\
\hline Meio Ambiente (1997/1998) & $\begin{array}{l}\text { Construção de referência comum no tratamento das questões ambientais, a } \\
\text { ser adotada no Ensino Fundamental. }\end{array}$ \\
\hline $\begin{array}{l}\text { Lei } n^{\circ} \text { 9.795/99 - Política Nacional de Educa- } \\
\text { ção Ambiental (PNEA) Decreto n } 4281 / 2002 .\end{array}$ & $\begin{array}{l}\text { Oficialização das diretrizes, objetivos e estratégias para a EA em âmbito naci- } \\
\text { onal. } \\
\text { Orientação da EA para a sustentabilidade. }\end{array}$ \\
\hline Programa Nacional de Educação & $\begin{array}{l}\text { Regulamentação da PNEA. } \\
\text { Detalhamento e operacionalização da PNEA. }\end{array}$ \\
\hline Ambiental (ProNea, 2004) & $\begin{array}{l}\text { Definição de açães para integração, desenvolvimento, participação da socie- } \\
\text { dade rumo à sustentabilidade ambiental. }\end{array}$ \\
\hline
\end{tabular}

Fonte: Gelze Serrat S. C. Rodrigues (2008).

Os Parâmetros Curriculares Nacionais (PCN) referente ao Meio Ambiente (1997/1998) representaram marco importante com relação às questões ambientais, uma vez que ele representou a construção de referência comum em todo o país referente a metodologia de trabalho dos docentes. O Ministério da Educação (MEC) disponibilizou aos docentes das escolas públicas de todo o Brasil o referencial no formato impresso e apoiou os grupos de estudos e formações continuadas nas escolas sobre o material disponibilizado.

A oficialização das diretrizes, objetivos e estratégias para a educação ambiental em âmbito nacional e orientação para a sustentabilidade, bem como os cuidados ambientais e Política Nacional de Educação Ambiental (PNEA), foram garantidos pela Lei no 9.795, de 27 de abril de 1999. Neste contexto, evidenciase a diversidade de leis brasileira as quais garantem a conscientização e o trabalho social em defesa das causas ambientais, entre elas destaca-se, a PNEA, que tornou a educação ambiental obrigatória, conforme pode ser observado do art. $1^{\circ}$ da Lei

Art. $1^{\circ}$ Entende-se por educação ambiental os processos por meio dos quais o indivíduo e a coletividade constroem valores sociais, conhecimentos, habilidades, atitudes e competências voltadas para a conservação do meio ambiente, bem de uso comum do povo, essencial à sadia qualidade de vida e sua sustentabilidade (BRASIL, Lei no 9.795/1999).

Nesse sentido compreende-se que a educação ambiental é elemento indispensável à população, devendo estar presente em todos os níveis e modalidades do processo educativo, em caráter formal e não 
formal, visando à formação de cidadãos preocupados com a realidade socioambiental de forma comprometida com a vida do planeta.

\section{EDUCAÇÃO AMBIENTAL E AS AÇÕES PEDAGÓGICAS}

Barbosa (2008) ressalta que as políticas públicas da educação no Brasil fomentadas pelo órgão gestor da PNEA vêm balizando educação crítica, participativa, transformadora e emancipatória, em sintonia com os princípios do Tratado de Educação Ambiental para Sociedades Sustentáveis e Responsabilidade Global.

Em relação às conquistas e ganhos pedagógicos pertinentes a questão ambiental, Leite (2015) afirma que em 1997, após várias discussões, foram aprovados os PCN, aportando subsídios para apoiar as escolas na elaboração dos projetos pedagógicos, e inserindo temas urgentes da realidade contemporânea para serem discutidos como temas transversais nas disciplinas.

Para Lemos e David, (2011, p. 7), “os PCN apresentam três conceitos para se compreender a questão ambiental: (a) Meio Ambiente; (b) Sustentabilidade; e (c) Diversidade”. O fato da sociedade conviver com as catástrofes ambientais, torna importante a discussão sobre o meio ambiente com os alunos em todas as etapas do ensino, daí a importância de se retomar os PCN. Lemos e David (2011) afirmam que os PCN, trazem temas fundamentais para serem desenvolvidos na escola e explicam que

$\mathrm{Na}$ abordagem acerca da questão ambiental os PCNs indicam que os problemas de esgotamento dos recursos naturais renováveis, problemas da miséria, da fome, de geração do lixo, dentre outros, são decorrentes da concentração de renda ligada ao modo de gerar riqueza e chamam a atenção para as manifestações ambientalistas da sociedade civil (LEMOS e DAVID, 2011, p. 4).

Os PCN, asseguram também os chamados temas transversais, entre eles constam os voltados para a temática meio ambiente, como forma de incentivar o respeito ao ambiente e as pessoas que convivem em comunidade, estimulando atitudes sustentáveis, ou seja, sem deixar de consumir, porém, sem desperdiçar. Segundo os PCN, fazem parte dos conteúdos procedimentais, formas de manutenção da limpeza do ambiente escolar (jogar lixo nos cestos, cuidar das plantas da escola e manter o banheiro limpo, por exemplo) ou formas de evitar o desperdício (BRASIL, 1997).

Cavalcanti (2003) ressalta que é dado um papel de destaque, ao docente, a responsabilidade de inserir a educação ambiental na sua prática de ensino, como recomenda a PNEA instituída pela Lei 9.795 em 1999 e regulamentada pelo Decreto $n^{\circ} 4.281$, de 2002. O art. $8^{\circ}, \S 2^{\circ}$ da PNEA estabelece que

A capacitação de recursos humanos voltar-se-á para: I - a incorporação da dimensão ambiental na formação, especialização e atualização dos educadores de todos os níveis e modalidades de ensino; II - a incorporação da dimensão ambiental na formação, especialização e atualização dos profissionais de todas as áreas; III - a preparação de profissionais orientados para as atividades de gestão ambiental; IV - a formação, especialização e atualização de profissionais na área de meio ambiente; $\mathrm{V}$ - o atendimento da demanda dos diversos segmentos da sociedade no que diz respeito à problemática ambiental, sustentabilidade (BRASIL, Lei no 9.795/1999).

Vinte anos após a homologação da PNEA, verifica-se no cotidiano das escolas brasileiras, que várias ações foram preconizadas em direção à formação docente para o exercício diário da educação ambiental nas escolas públicas brasileiras. A esse respeito Lemos e David que 
A Educação Ambiental e importante, pois ajuda os alunos a elaborarem uma ideia sobre os fatores do seu meio para estabelecer uma ligação entre o que ele aprendeu e o seu cotidiano. O conhecimento ambiental ajuda o aluno a compreender a realidade e a atuar sobre ela, assim como participar das atividades na escola e de ações na comunidade (LEMOS e DAVID, 2011, p. 12).

Importante marco de incentivo a ações pedagógicas foi à criação da Comissão de Meio Ambiente e Qualidade de Vida (COM-VIDA), que teve como objetivo potencializar as ações de educação ambiental nas escolas do ensino fundamental $\left(6^{\circ}\right.$ ao $9^{\circ}$ ano) e de Ensino Médio, por meio da criação e manutenção de espaço democrático e participativo que congregue toda a comunidade escolar e fomente iniciativas voltadas para a sustentabilidade socioambiental e à melhoria da qualidade de vida na escola e sua comunidade, assim como o diálogo sobre temas socioambientais contemporâneos, a esse respeito é correto afirmar que

A Com Vida procura relacionar questões práticas da realidade que cerca o ambiente escolar e comunitário. Para isso, a metodologia de trabalho adotada é a proposta da Agenda 21, que já é uma ferramenta consagrada na área ambiental. Ela procura estimular que as pessoas e organizações envolvidas encontrem de forma participativa os principais problemas ambientais locais e busquem as soluções viáveis para eles. Portanto, a Agenda 21 não é apenas uma ferramenta técnica, mas é sobretudo política, na medida em que compartilha o poder (de fala, de decisões, etc.), contribuindo para tornar o dia-a-dia da escola mais democrático e participativo. Em 2006 foi criada a Rede Brasileira de Agendas 21 Locais, refletindo o amadurecimento destas iniciativas em todo o país (BRASIL, 2007. p.12).

As escolas públicas brasileiras via incentivo das equipes gestoras e pedagógicas que se dedicaram a construção da agenda 21 garantiram por meio de relatórios, que a mesma contribuiu para a criação e desenvolvimento de projetos grandiosos em defesa das causas ambientais. No que diz respeito às demandas sociais, Luck (2000) assegura que

A escola, como unidade básica e espaço de realização de objetivos e metas do sistema educativo, encontra-se hoje como centro da atenção da sociedade, constituído e de grande valor estratégico para o nosso desenvolvimento, assim como importante também para a qualidade de vida e demandas sociais das pessoas que orbitam o seu entorno comunitário (LÜCK, 2000, p. 27).

Os gestores das escolas públicas de ensino fundamental II e Médio, participaram da promoção da integração de estudantes, professores, funcionários e a comunidade nas questões ambientais, visando o trabalho coletivo em defesa da sustentabilidade do meio ambiente. Para Barbosa (2008, p. 10) as Com-Vidas representam processos de Conferência Nacional Infanto-Juvenil pelo Meio Ambiente, no intuito de formar jovens para a cidadania ambiental. "juventude ambientalista” emergente está sintonizada com os desafios da gestão de políticas públicas da área socioambiental. Ela se sente empoderada e assume novas responsabilidades nos espaços nos quais atuam.

Em sua pesquisa sobre os desafios prioritários pertinentes as tendências atuais da educação ambiental nos sistemas de ensino nas Secretarias de Estados da Educação, Barbosa (2008) afirma que esta ainda consiste na formação continuada como a principal prioridade e destaca que

Os dados apresentados acerca dos desafios prioritários sinalizam tendências atuais da EA nos sistemas de ensino: incremento dos processos de formação continuada de professores em EA, já que 23 UFs (ou $85 \%$ ) identificam a formação continuada como a principal prioridade; institucionalização da EA nas SEDUCs, que foi escolhida por 7 UFs ( $26 \%$, aproximadamente) como prioridade $n^{\circ} 1$; inserção curricular qualificada e fortalecimento de Com-Vidas, que obtiveram, respectivamente, 17 (63\%) e 10 (37\%) 
das indicações de UFs entre as três principais prioridades identificadas. Dois outros desafios listados no questionário da pesquisa (mas não mencionados nos quadros) não foram citados por nenhuma SEDUC entre suas três principais prioridades: "participação da SEDUC na construção do Sisnea" e "plano de metas, cronograma das ações de EA". Em alguma medida, convém relativizar a ordem enumerada pelas secretarias de educação21, mas causa estranheza nenhuma SEDUC ter priorizado a construção de um sistema nacional de EA (Sisnea) seis meses após terem pactuado - juntamente com as secretarias estaduais de meio ambiente, OG da PNEA (MEC e MMA) e representantes da sociedade civil (indicados pelas CIEAs - um por UF) - uma agenda de debates e consulta pública sobre a proposta (BARBOSA, 2008, p. 16-17).

O autor, enfatiza que apesar da Secretaria de Estado da Educação (SEDUC), insistir que entre suas prioridades consta a formação docente, evidencia-se, nas escolas públicas o pouco envolvimento em relação ao acompanhamento do plano de metas, cronograma das ações de educação ambiental nas escolas, principalmente na Educação Infantil e Alfabetização.

De acordo com as pesquisas, compreende-se que faz-se necessário fortalecer os canais de comunicação entre escola e comunidade, promovendo a gestão democrática, pois quando há compartilhamento de ações há maior comprometimento dos envolvidos, nesse sentido Libâneo (2008) assegura que "é imprescindível a participação da comunidade escolar no processo de tomada de decisão, na construção coletiva dos objetivos e das práticas escolares, no diálogo e na busca de consenso" (LIBÂNEO, 2008, p.132).

Teixeira e Torales (2014, p.128) evidenciam que em junho de 2012, foram definidas as Diretrizes Curriculares Nacionais para a Educação Ambiental, em continuidade ao movimento de institucionalização da educação ambiental no país, iniciada nos anos 1990. A educação ambiental é necessária em processo contínuo e com o apoio da equipe gestora, considerando que este passa pelo Capital Cultural do indivíduo que deve ser construído dia a dia e de forma planejada e sistematizada.

Bourdieu (2004, p. 23) afirma que "isso é realizado pelos agentes do campo que lutam para conservar ou transformar as forças que o constituem, nele criando espaços. O fazem a partir de uma posição no campo que condiciona as possibilidades de sucesso nesta luta". Para este autor a origem do conceito de campo, foi elaborado para resolver problema colocado pela explicação da produção dos bens simbólicos na sociedade. Logo, a produção cultural se constrói também na escola, no labor diário.

A sociedade protagonizou durante décadas, principalmente na região norte do Brasil, que desmatar era sinônimo de riqueza, este foi o legado deixado pelos pais na era do chamado desenvolvimento, os desbravadores quanto mais desmatavam maior era seu capital econômico. Neste período não se percebia preocupação com as questões ligadas a sustentabilidade.

Nas últimas décadas, políticas públicas, com a função de proporcionar a reflexão acerca da responsabilidade da comunidade em defesa da sustentabilidade do planeta emergem não apenas por força da lei, mas pela coerência, por consciência dos povos. As principais iniciativas ligadas à educação ambiental, emergem da incentivada de gestores escolares, os quais promovem entre outras ações, as formações docentes, as quais são promotoras de ações eticamente corretas no que diz respeito a conscientização de viver de forma sustentável, assim,

A reflexão e a prática da educação ambiental não são resultados exclusivos das políticas públicas. Todavia, elas estabelecem as orientações e impulsionam projetos, programas, formação continuada de professores, material didático e outras estratégias, com maior ou menor sistematização e sucesso, para desenvolver a educação ambiental nas instituições de ensino, inclusive nos cursos de formação de professores nas universidades. Embora a educação ambiental se expanda, ela ainda é pouco abrangente e se 
caracteriza por ações pontuais e incipientes como prática a ser potencializada (TORALES, 2013 apud TEIXEIRA E TORALES 2014, p. 129).

Para que a educação ambiental, ocorra de forma impactante, no sentido de ampliar a consciência ambiental, faz-se necessário incentivar novos comportamentos, e as escolas, por serem espaços de formação, são locais ideais para solidificar hábitos politicamente corretos.

\section{CONSIDERAÇÕES FINAIS}

Entre os objetivos da presente pesquisa, consta o estudo da liderança que se faz aflorar do gestor escolar, compelindo-o no trato do seu trabalho, quer pedagógico ou administrativo, pois cabe ao gestor escolar, com foco na qualidade educacional e de vida, garantir a promoção de formações continuadas para os docentes com temas relacionados à educação ambiental e outras temáticas, que abranja educadores de todos os níveis da educação básica.

Assim, como viabilizar a aquisição e utilização de aparatos tecnológicos para garantir que os conhecimentos docentes permaneçam atualizados e eficientes, capazes de promover o despertar de habilidades e competência relacionadas aos cuidados com o planeta e a sustentabilidade ambiental. O foco da gestão escolar pauta-se na relação que é desenvolvida nos limites da escola e seu entorno, abrangendo temáticas atuais.

No que tange as questões ambientais, verifica-se que os avanços das ciências e tecnologias vivenciadas neste século, promovem ao mesmo tempo facilidades no modo de viver das pessoas, como riscos que se estendem para além dos medos e angústias gerados na vida social, exigindo dos mantenedores de ensino, a implementação de políticas públicas que assegurem planejamento e ações educativas conscientes que envolvam a sociedade civil por meio de mobilização, atos concretos de enfrentamento das fragilidades para garantir a continuidade da vida na Terra.

$\mathrm{Na}$ abordagem acerca das questões ambientais os PCN, balizam a possibilidade de esgotamento dos recursos naturais renováveis e chamam a atenção para as manifestações ambientalistas da sociedade civil, logo, a convivência do homem com o meio natural deve pautar-se nas interações, nas quais sejam levadas em consideração as matérias primas processadas, os objetos de uso, construções e cultivos, nesse interim é imprescindível trabalhar com os alunos a importância da preservação do patrimônio natural com vistas a conservação dos recursos naturais, e a preservação do patrimônio cultural, construído por diversas sociedades em diferentes tempos e lugares.

Para que as escolas se mantenham eficientes em ambientes caracterizados por constantes mudanças, precisam acompanhar eventos e tendências significativos que estão ocorrendo no ambiente interno e externo a escola.

\section{REFERÊNCIAS}

BARBOSA, Luciano Chagas, Políticas Públicas de Educação Ambiental numa Sociedade de Risco: Tendências e Desafios no Brasil. IV Encontro Nacional da Anppas. Brasília - DF. Brasil. 2008

BOURDIEU, P. Os usos sociais da ciência: Por uma sociologia do campo científico. São Paulo: Editora Unesp, 2004.

BRASIL. Parâmetros curriculares Nacionais: Meio Ambiente e Saúde. Secretaria de Educação 
Fundamental. Brasília, DF, 1997

. Lei n 9.795, de 27 de abril de 1999. Educação Ambiental: Política Nacional de Educação Ambiental. Diário Oficial da União, Brasília,28 de abril de 1999. Disponível em: <http://www.planalto.gov.br/ccivil_03/leis/L9795.htm>.

. Constituição (1988). Constituição da República Federativa do Brasil. Organização de Alexandre de Moraes. 16.ed. São Paulo: Atlas, 2000.

. Comissão de Meio Ambiente e Qualidade de Vida na Escola Com -Vida Série Documentos Técnicos, n 10. Órgão Gestor da Política Nacional de Educação Ambiental Brasília 2007

CAVALCANTI, Júlia Nazário de Abreu. Educação Ambiental: conceitos, legislação, decretos e resoluções pertinentes e a formação continuada de professores em educação ambiental na Paraíba. Revista Eletrônica do Mestrado em Educação Ambiental - Revista do PPGEA/FURG-RS. ISSN 15171256, 2003.

LEITE, Ivonaldo. História, educação ambiental e políticas: uma retrospectiva da realidade brasileira e uma abordagem sobre os seus desafios. Revista HISTEDBR On-line, Campinas, n 63, p. 306319, jun2015 - ISSN: 1676-2584

LEMOS, Enilda Maria, DAVID, Celia Maria, Reflexões sobre o tema transversal meio ambiente no ensino fundamental. Camine: Caminhos da educação: v. 2, 2011.

LIBÂNEO, José Carlos. Organização e Gestão da Escola: teoria e prática. 5. ed. Revista e ampliada. Goiânia: MF Livros, 2008.

LÜCK, Heloisa. (Org.). Gestão escolar e formação de gestores. Em Aberto, v. 17, n.72, p. 1-195, fev./jun. 2000.

MORAN, José Manuel. Novas Tecnologias e Mediação Pedagógica. Campinas: Papirus, $21^{a}$ ed, 2013, p. 36-46.

PÁDUA, José Augusto As bases teóricas da história ambiental. Estud. av. vol.24 no.68 São Paulo 2010.

RODRIGUES, Gelze Serrat de Souza Campos, COLESANT Marlene T. de Mundo Educação ambiental e as novas tecnologias de informação e comunicação, Sociedade \& Natureza, Uberlândia, 20(1): 51-66, jun. 2008

SAVIANI, D. (1998). O debate teórico e metodológico no campo da história e sua importância para a pesquisa educacional, in: SAVIANI, Demerval; LOMBARDI, José C.; SANFELICE, José L. (Orgs.). História e educação: o debate teórico-metodológico atual. Campinas-SP: Autores Associados.

TEIXEIRA, Cristina, TORALES Marília Andrade A questão ambiental e a formação de professores para a educação básica: um olhar sobre as licenciaturas. Educar em Revista. Curitiba. Brasil. Edição Especial n. 3/2014, p. 127-144. Editora UFPR. 